\title{
Tumor de células germinales extragonadal en mujer $\mathrm{VIH}^{+}$
}

\author{
M. I. FUENTES GARCÍA, J. L. MOSTAZA FERNÁNDEZ1, N. GARCÍA LÓPEZ, \\ C. OLIVARES FERNÁNDEZ, M. J. PALOMO DE LOS REYES
}

Servicio de Medicina de Familia y Comunitaria. Unidad Docente Ponferrada. ${ }^{I}$ Servicio de Medicina Interna Hospital El Bierzo. León

\author{
EXTRAGONADAL GERM CELL TUMOR IN HIV + FEMALE
}

\section{RESUMEN}

Los tumores de células germinales extragondales (TCGE) son poco frecuentes, sobre todo en mujeres. Aunque no existe evidencia de asociación entre este tipo de tumor y la infección por VIH, pueden coincidir en el mismo paciente debido a que, en ambos, la máxima incidencia se da en el mismo segmento de edad. Presentamos el caso de una mujer de 27 años, politoxicómana, con infección por VIH de reciente diagnóstico, que ingresa por clínica de infección e insuficiencia respiratoria y desarrolla durante su hospitalización, diarrea, crisis tónico-clónica generalizada y hemiparesia izquierda. En las pruebas complementarias practicadas se evidencia patrón intersticial pulmonar difuso, masa mediastínica con adenopatías intratorácicas, lesión ocupante de espacio (LOE) cerebral y engrosamiento intestinal difuso. La infección respiratoria mejoró con tratamiento antibiótico de amplio espectro que incluía cotrimoxazol y levofloxacino, pero la LOE cerebral no mejoró con tratamiento antitoxoplasma. La presentación clínica inicialmente simulaba la de un linfoma diseminado, en una paciente $\mathrm{VIH}+$, sin embargo, tras recibir el resultado de la biopsia de una adenopatía supraclavicular y de b-HCG se realizó el diagnóstico de tumor de células germinales extragonadal. En la revisión bibliográfica realizada (MEDLINE) no hemos encontrado ningún caso de TCGE en mujeres jóvenes con infección por VIH.

PALABRAS CLAVE: Extragonadal germ cell tumors. Disgerminoma. HIV. Female.

\begin{abstract}
Extragodanal germ cell tumors (EGCT) are not common, especially among women. Although there is no evidence of relationship between this sort of tumor and HIV infection they can appear at the same time in a patient, because in both cases the maximum incidence occurs in patients in the same age group. We present the case of a 27 years old woman, poly-drug user, with a recently diagnosis of HIV infection, who was admitted to clinic because of infection and shortage of breath, and developes during her hospitalization diahorrea, generalized tonic-clonic seizure and left hemiparesis. Complementary tests showed us diffuse interstitial pulmonary pattern, mediastinal mass with intrathoracic adenopathies, cerebral tumor and diffuse intestinal enlargementent. The breath infection got better with a wide-ranging antibiotic treatment, which included cotrimoxazol and levofloxacin, but the brain tumor didn't get better with the antitoxoplasma treatment. The clinical presentation simulated in the beginning a disseminated lymphoma, in a HIV+ patient; nevertheless, after receiving the result of the biopsy of a supraclavicular adenopathy and a b-HCG, an extragodanal germ cell tumor was diagnosed. We haven't found any case of EGCT in young women infected with HIV in our bibliographical review (MEDLINE).
\end{abstract}

KEY WORDS: Extragonadal germ cell tumors. Disgerminoma. HIV. Female.

Fuentes García MI, Mostaza Fernández JL, García López, N, Olivares Fernández C, Palomo de los Reyes MJ. Tumor de células germinales extragonadal en mujer VIH+. An Med Interna (Madrid) 2004; 21: 397-399.

\section{INTRODUCCIÓN}

Los tumores de células germinales extragonadales (TCGE) derivan del endodermo extraembrionario y se pueden desarrollar en cualquier área de la línea media (glándula pineal $40 \%$, mediastino $30 \%$, retroperitoneo $20 \%$, otras $10 \%$ ) $(1,2)$. Pueden ser benignos (teratoma) o malignos, clasificándose éstos últimos en seminomatosos y no seminomatosos. Son poco frecuentes, representan del 2-5\% de los tumores de células germinales del adulto y son excepcionales en mujeres (1/6 de los casos en las series revisadas) $(3,4)$. Clínicamente no dan sintomatología por si mismos, resultando ser un hallazgo casual tras adquirir grandes dimensiones y comprimir estructuras adyacentes.

El diagnóstico puede ser difícil y se debería considerar en cualquier paciente con un tumor epitelial indiferenciado, particularmente en individuos jóvenes con masas en la línea media $(5,6)$. Aunque no existe evidencia de asociación entre el TCGE y la infección por VIH, pueden coincidir en el mismo paciente pues la máxima incidencia se produce en el mismo segmento de edad.

Presentamos un caso de TCGE en fase diseminada, diagnos-

Trabajo aceptado: 24 de marzo de 2004 
ticado en una mujer joven VIH+. Este caso nos parece relevante por su excepcionalidad (en la revisión bibliográfica de MEDLINE no hemos encontrado ningún caso de TCGE en mujeres jóvenes con infección por $\mathrm{VIH}$ ), porque simula la presentación de un linfoma diseminado y porque en los pacientes con infección por VIH, además de la patología típica y propia, también hay que pensar en la patología que afecta a su mismo segmento de edad.

\section{CASO APORTADO}

Mujer de 27 años, politoxicómana activa, que 15 días antes de ingresar comienza con tos seca, disnea de intensidad progresiva, fiebre, astenia, anorexia, náuseas y vómitos. Tenía antecedentes de infección por VIH de reciente diagnóstico, desconociendo sus parámetros inmunológicos y virológicos. La exploración al ingreso mostraba caquexia, 40 respiraciones/ min., 120 latidos/min. TA:110/60 mm Hg, muguet, acropaquias, adenopatías cervicales bilaterales menores de $1 \mathrm{~cm}$ y supraclavicular derecha de $2 \mathrm{~cm}$. Disminución generalizada del murmullo vesicular y crepitantes bibasales, soplo sistólico II/VI polifocal, hepatomegalia a $2 \mathrm{~cm}$ del borde costal y condilomas vulvares. El resto de la exploración somática y neurológica fueron normales. Se realizaron al ingreso las siguientes pruebas complementarias: $\mathrm{Hb} 11,3 \mathrm{~g} / \mathrm{dL}$, 6.900 leucocitos/ $\mu \mathrm{L}$ (79\% segmentados, $14 \%$ linfocitos), 682.000 plaquetas/ $\mu \mathrm{L}$; sodio $119 \mathrm{mmol} / \mathrm{L}, \mathrm{LDH} 603 \mathrm{UI} / \mathrm{L}$, siendo normales el resto de los valores del autoanalizador. Gasometría arterial basal al ingreso: pH 7,54, pCO2 34,8 mm Hg, pO2 73,4 mmHg. En la placa de tórax se observa una masa mediastínica anterior derecha que comprime y desplaza la tráquea y un infiltrado alveolo-intersticial bilateral (Fig. 1). Posteriormente se realiza ecografía abdominal y TAC torácico, abdominal y pélvico en los que se aprecian adenopatías axilares bilaterales menores de un $\mathrm{cm}$, una gran masa mediastínica que comprime tráquea y vena cava superior, patrón intersticial pulmonar en resolución y engrosamiento de pared de asas intestinales con pequeña cantidad de líquido libre entre ellas. Se realizó ecocardiograma transtorácico en el que no se encontraron alteraciones. Se inicia tratamiento con cotrimoxazol, levofloxacino y amfotericina-B, a pesar de lo cual desarrolla insuficiencia respiratoria progresiva, precisando ventilación mecánica. Durante los días siguientes se observa mejoría de la insuficiencia respiratoria, posibilitando la retirada de la ventilación mecánica. Posteriormente presenta crisis tónico-clónica generalizada seguida de hemiparesia izquierda; se realiza TAC y RMN craneal, observándose una masa de pared gruesa y centro hipodenso de $4 \mathrm{~cm}$ de diámetro en encrucijada témporoparieto-occipital derecha (Fig. 2). Se añade al tratamiento sulfadiacina, pirimetamina, ácido fólico y fenitoína, que se retiran tres semanas más

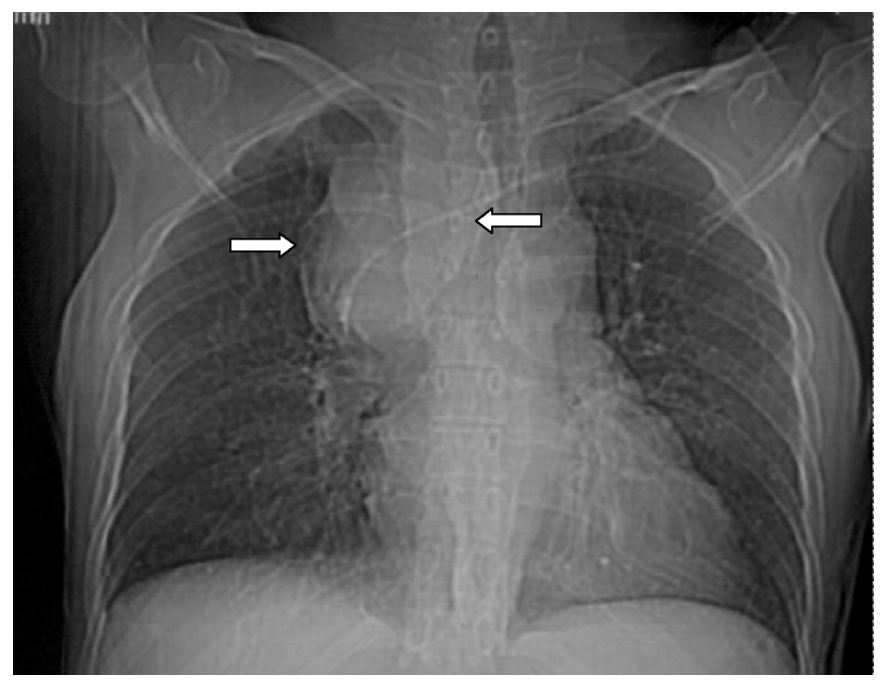

Fig. 1. Rx tórax: masa mediastínica anterior derecha. Infiltrado alvéolo-intersticial bilateral.

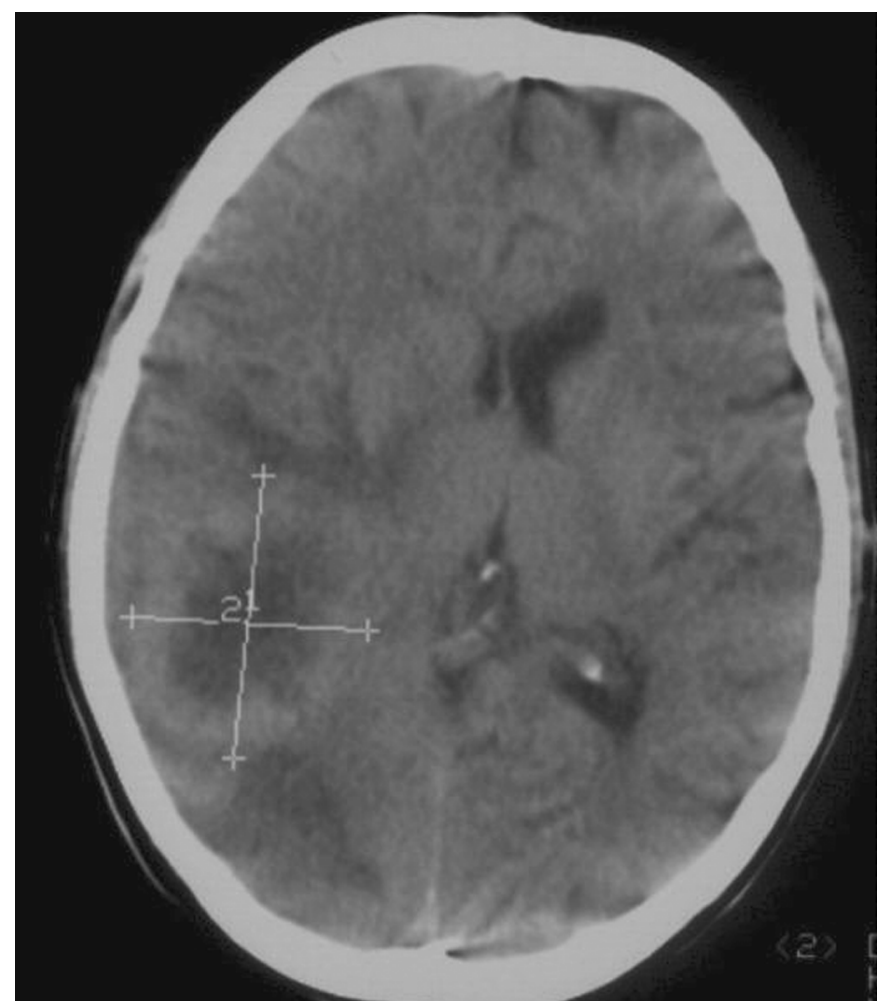

Fig. 2. TAC craneal: masa de pared gruesa y centro hipodenso de 4 $\mathrm{cm}$ de diámetro en encrucijada témporo-parieto-occipital derecha.

tarde por ausencia de mejoría clínica y de disminución de la lesión intracraneal. Se realizó PAAF y biopsia de adenopatía supraclavicular que se informa como metástasis de tumor maligno indiferenciado de origen epitelial. Más tarde se reciben los resultados siguientes: linfocitos CD4+: 440/mL, carga viral VIH: 25.000 copias/ mL, alfafetoproteina normal y b-HCG: $650 \mathrm{mUI} / \mathrm{mL}$ (normal $<5$ ). Los estudios microbiológicos en sangre, orina, esputo, brocoaspirado y punción ganglionar fueron negativos para bacterias, micobacterias y hongos. Las tinciones de muestras respiratorias fueron negativas para P. carinii (P. jiroveci). Las serologías para Toxoplasma, virus hepatotropos y RPR fueron negativas; el antígeno criptocócico fue negativo.

Diagnóstico y evolución: Inicialmente se realizó el diagnóstico de neumonía difusa presuntivamente por $P$. carinii $(P$. jiroveci) y probable linfoma diseminado con afectación mediastínica, cerebral e intestinal. Tras recibir los resultados de la biopsia ganglionar y de los marcadores tumorales (alfafetoproteina y $\beta$-HCG), se realiza el diagnóstico definitivo: tumor de células germinales extragonadal con afectación ganglionar supraclavicular y mediastínica, y probablemente cerebral. Se propone a la paciente realizar estudio de extensión tumoral e iniciar tratamiento con poliquimioterapia, que rechaza , a pesar de explicársele que la elevada quimiosensibilidad del tumor lo hacía potencialmente curable. La paciente falleció en otro centro varias semanas después del alta.

\section{DISCUSIÓN}

La presentación clínica de este caso simula una infección oportunista pulmonar, en el seno de una infección posiblemente avanzada por VIH (caquexia, muguet, neumonía difusa...), con aparición de una masa cerebral, mediastínica y probablemente intestinal, compatible con un linfoma diseminado.

Aunque presentaba una cifra de linfocitos CD4 poco deteriorada, la existencia de una neoplasia diseminada se asocia a 
inmunodepresión celular, por lo que en este caso, tanto por su presentación, como por su respuesta al tratamiento, no se puede descartar una infección pulmonar por P. carinii (P. jiroveci).

Aunque la causa más frecuente de lesión intracraneal focal en pacientes VIH+ es la toxoplasmosis cerebral (7), en esta paciente el diagnóstico era poco probable al presentar una serología de Toxoplasma negativa, una cifra de linfocitos CD4+ no suficientemente deteriorada y ausencia de respuesta clínica después de tres semanas de tratamiento con pirimetamina y sulfadiacina.

En los pacientes con infección por VIH, las causas más probables de una masa mediastínica son infecciones (el 87\% por micobacterias) o tumores, siendo el más frecuente el linfoma (39\%), seguido por el cáncer de pulmón, los tumores de células germinales y el sarcoma de Kaposi $(8,9)$.

\section{Bibliografía}

1. Tumores extragonadales de células germinales. Cancer.gov. http://www.nci.nih.gov/español/pdq/tratamiento/extragondal/healthprofessional/

2. Mayordomo JI, Paz-Ares L, Rivera F, López-Brea M, López Martín E, Mendiola C,et al. Ovarian and extragonadal malignant germ-cell tumors in females: a single-institution experience with 43 patients. Ann Oncol 1994; 5: 25-31.

3. Goss Pe, Schwertfeger L, Blackstein Me, Ginsberg RJ, Simpson WJ, Jones DP, et al. Extragonadal germ tumors. A 14-year Toronto experience. Cancer 1994; 73: 1971-9.

4. Yu-Juei Hsu MD, Lu Pai Ph D, Yeu-Chin Chen MD, Ching-Liang Ho, MD, Woei-Yau Kao MD, Tsu-Yi Chao MD, DMS. Extragonadal germ cell tumors in Taiwan. Cancer 2002; 95: 776-774.

5. Greco FA, Vaughn WK, Hainsworth JD: Advanced poorly differentiated carcinoma of unknown primary site: recognition of a treatable syndrome. Ann Intern Med 1986; 104: 547-53.

6. Hainsworth JD, Greco FA: Extragonadal germ cell tumors ann unrecognised germ cell tumors. Semin Oncol 1992; 19: 119-27.
No hay evidencia de que el TCGE se asocie a la infección por VIH (10), aunque algunos autores hacen referencia a un aumento de la incidencia en esta población (11). Sin embargo, ambas enfermedades pueden coincidir en el mismo paciente, al incidir en el mismo segmento de edad. El TCGE puede simular un linfoma, cuando aparece en pacientes VIH positivos (12). El pronóstico del TCGE en pacientes VIH positivos, está en relación con el grado de inmunodeficiencia del paciente (13).

En definitiva, en los pacientes con infección por VIH que se presentan con una masa mediastínica, también hay que pensar en las patologías prevalentes en ese segmento de edad, y por tanto considerar la posibilidad de que se trate de un tumor de células germinales.

7. Crespo Valadés E, Vera Tomé P. Díaz Pinto, F. Sánchez Montero, A. Muñoz Sanz. Masa intracraneal en paciente con infección por VIH. Rev Clin Esp 2000; 200: 33-4.

8. Fishman JE, Sagar M. Thoracic lymphadenopathy in HIV patients: spectrum of disease and differential diagnosis. AIDS Patient Care STDS 1999; 13: 645

9. Weidner N. Germ-cell tumors of the mediastinum. Semin Diagn Pathol 1999; 16: 42-50.

10. Guntel CJ, Northfeclt DW. Cancers not associated with inmunodeficiency in HIV infected persons. Oncology 1994; 8: 59-64.

11. Volm M, Von Roenn J. Non-AIDS-defining malignancies in patients with HIV infection. Curr Opin Oncol 1996; 8: 386-91.

12. Díaz JI, Nicosia SV, Szakacs J, Powsang J, Saba HI. Metastatic seminoma simulating malignant lymphoma in an HIV infected hemophiliac. Leuk Lymphoma 1996; 23: 165-71.

13. Fiazi K, Amato RJ, Beuzeboc P, Petit N, Bouhour D, Thiss A, Rebischung $\mathrm{C}$, et al. Germ cell tumors in patientsninfected by the human immunodeficiency virus. Cancer 2001; 92: 1460-7. 